\title{
O planejamento de práticas pedagógicas alfabetizadoras em tempos de pandemia: desafios e possibilidades
}

\section{Planning literacy teaching practices in pandemic times: challenges and possibilities}

\author{
Patrícia Ignácio \\ Doutorado em Educação \\ Universidade Federal do Rio Grande - FURG. \\ Santo Antônio da Patrulha, RS - Brasil. \\ patriciaignacio.furg@gmail.com \\ Caroline Braga Michel \\ Doutorado em Educação \\ Universidade Federal do Rio Grande - FURG. \\ Santo Antônio da Patrulha, RS - Brasil. \\ caroli_brga@yahoo.com.br
}

\begin{abstract}
Resumo: Este artigo apresenta resultados de uma pesquisa cujo objetivo foi compreender os desafios e as possibilidades encontradas por alfabetizadoras, de dois municípios do Rio Grande do Sul, no planejamento de suas práticas pedagógicas em tempos da COVID-19. A coleta de dados ocorreu por meio de questionário on-line. A análise, de cunho qualitativo e exploratório, pautou-se nas respostas de 28 professoras, tendo como subsídio os trabalhos de Menegolla e Sant'Anna (2014), Soares (2016), Nóvoa (2020), Dussel (2020), Moreira e Schlemmer (2020), entre outros. Os resultados mostraram que os principais desafios diziam respeito ao distanciamento físico, à quantidade de atividades propostas, ao tempo destinado à realização destas, bem como à necessidade de mediação, por parte das famílias, na execução do planejamento. Quanto às possibilidades, salienta-se o uso de ferramentas tecnológicas tanto para a manutenção do vínculo, quanto para o desenvolvimento das tarefas de forma autônoma.
\end{abstract}

Palavras chave: alfabetização; pandemia; planejamento; prática pedagógica.

Abstract:: This paper brings the results of a study aimed at understanding the challenges and possibilities encountered from literacy teachers, two municipalities in the Brazilian State of Rio Grande do Sul, in planning their pedagogical practices in times of COVID-19. Data collection was carried out through an online survey. Based on the responses of 28 teachers, an analysis of qualitative and exploratory nature was undertaken, having as support the works of Menegolla and Sant'Anna (2014), Soares (2016), Nóvoa (2020), Dussel (2020), and Moreira and Schlemmer (2020), between others. The results showed that the main challenges were related to physical distance, the amount of activities proposed, the time allotted to carry them out, as well as the need for mediation by the families in carrying out the planning. As for the possibilities, the use of technological tools is highlighted both for the maintenance of the bond and for the development of tasks in an autonomous way.

key words: literacy; pandemic; planning; teaching practice.

Cite como

(ABNT NBR 6023:2018)

IGNÁCIO, Patrícia; MICHEL, Caroline Braga. O planejamento de práticas pedagógicas alfabetizadoras em tempos de pandemia: desafios e possibilidades. Dialogia, São Paulo, n. 39, p. 1-18, e20620, set./dez. 2021. Disponível em: https://doi.org/10.5585/39.2021.20620.

American Psychological Association (APA)

Ignácio, P., \& Michel, C. B. (2021, set. / dez.) O planejamento de práticas pedagógicas alfabetizadoras em tempos de pandemia: desafios e possibilidades. Dialogia, São Paulo, 39, p. 1-18, e20620. https://doi.org/10.5585/39.2021.20620. 


\section{Introdução}

Considerando o cenário de suspensão das atividades presenciais das instituições de Educação Básica e Ensino Superior de todo o Brasil no ano de 2020, em virtude da Pandemia do Coronavírus (COVID-19), os processos de ensino e de aprendizagem de crianças e jovens foram obrigatoriamente engendrados a partir de outros espaços e tempos que não mais os das salas de aula. Tratando-se de crianças em processo de alfabetização, essa nova conjuntura apresentou novos limites, tendo em vista as especificidades e as expertises implicadas no acompanhamento e na avaliação da aprendizagem das crianças que integram este ciclo.

Em meio a um contexto de incertezas e enfrentando os mais multifários desafios, as redes de ensino estaduais e municipais do Rio Grande do Sul, assim como as demais instituições de Educação Básica e de Ensino Superior do Estado, tiveram suas atividades de ensino presencial, repentinamente, suspensas no mês de Março do ano de 2020, segundo o Decreto Estadual n ${ }^{\circ}$ 55.115, de 12 de março. Suspensão esta que foi sendo prorrogada, levando muitas instituições a concluírem o ano letivo de modo on-line e a deixarem para o próximo ano a possibilidade de retorno das atividades presenciais. Logo, a estratégia utilizada pelas redes para dar continuidade às suas atividades, em caráter emergencial, foi o ensino remoto.

Segundo Moreira e Schlemer (2020, p. 8), o ensino remoto se configura como uma "modalidade de ensino ou aula que pressupõe o distanciamento geográfico de professores e estudantes e vem sendo adotada nos diferentes níveis de ensino, por instituições educacionais no mundo todo, em função das restrições impostas pelo COVID-19”. Ainda, conforme os autores, pode-se dizer que nesse formato, há a transposição do ensino presencial para os meios digitais (Ibid.). Ou seja, o mesmo professor ou professora que atendia a turma de maneira física, passa a ministrar as aulas por meio digital. Todavia, vale salientar que essa "transposição do presencial para o digital" foi foco de um amplo debate no decorrer de 2020, uma vez que a dinâmica de funcionamento de ambos apresenta singularidades.

A situação enfrentada no Rio Grande do Sul não foi diferente da de outros Estados. Os resultados do Relatório Parcial da pesquisa Alfabetização em Rede (2020), sobre a situação da alfabetizacão de criancas no Brasil durante a pandemia da Covid-19, realizada com 14.730 docentes-respondentes das cinco regiões do país, dentre os quais $93 \%$ são oriundos das redes municipais de ensino, mostram que $90 \%$ dos entrevistados estavam atuando de forma remota em 2020. Para pouco mais da metade dos participantes da pesquisa $(54,9 \%)$, esta modalidade representava uma forma de manter o vínculo com os alunos. Por sua vez, 44,6\% consideravam as atividades remotas como uma saída possível para os problemas advindos da pandemia. Contudo, 
asseveravam não alcançar os objetivos escolares, tendo em vista as especificidades do processo de alfabetização e as expertises que o envolvem, bem como as diferentes demandas que emanam dos espaços e dos tempos das casas em tempos de isolamento.

Diante dessa realidade e da orientação de dar continuidade às atividades de ensino no ano de 2020 de modo remoto, professoras e professores do ciclo de alfabetização, bem como gestores tiveram suas ações tensionadas, considerando a iminente necessidade de (re)organização, (re)configuração e (re)invenção de seus planejamentos. Nesse contexto, as atividades passaram a ser enviadas e entregues aos alunos por meio impresso e/ou digital, podendo ser retiradas pelos responsáveis, entregues em casa pelas profissionais e/ou encaminhadas por meio de ferramentas tecnológicas.

A este respeito, estudos e pesquisas têm contribuído para mapear as ações das gestões estaduais e municipais e, também, as práticas pedagógicas desenvolvidas pelas professoras alfabetizadoras de modo a tentar compreender como o processo de alfabetização foi instituído em meio à pandemia da Covid-19 no ano de $2020^{1}$. Ademais, eles têm possibilitado focalizar inúmeras facetas da educação, por vezes preteridas, tais como, por exemplo, o direito e o acesso à educação de qualidade, a desigualdade social, as políticas públicas de formação continuada, a falta de recursos e investimentos na infraestrutura das instituições de ensino, o uso das tecnologias nos espaços escolares, a sobrecarga e a desvalorização do trabalho docente, a relação família-escola, entre outras (SOUZA e MAGNONI JÚNIOR, 2020; MELO e FRANÇA-CARVALHO, 2020; AMORIM e AMARAL, 2020; SOBRINHO, 2020; FERREIRA e BARBOSA, 2020).

Partindo desse contexto, apresenta-se, neste artigo, os resultados de uma pesquisa que teve como intuito compreender os desafios e as possibilidades encontradas por professoras alfabetizadoras, de dois municípios do Rio Grande do Sul, no planejamento de suas práticas pedagógicas em tempos da Covid-19, logo nos primeiros meses do isolamento social. Para tanto, foi enviado um questionário on-line via Google Forms a todas as professoras que atuavam no ciclo de alfabetização das duas redes de ensino pesquisadas.

Diante do exposto, salienta-se que este texto está organizado em três seções. Na primeira são apresentados os conceitos que subsidiaram a categorização e a análise dos dados. Na segunda, são expostos os aspectos metodológicos da pesquisa realizada, e, por fim, na terceira são elucidados os desafios e as possibilidades dos planejamentos identificados nas narrativas das alfabetizadoras.

\footnotetext{
${ }^{1}$ Para mais sobre o assunto sugere-se ver Guizzo, Marcelo e Muller (2020), Ludovico, Molon, Franco, Barcellos (2020), entre outros. ${ }^{2}$ O questionário integrou o curso de formação continuada "Alfabetização em tempos de Pandemia", ofertado às professoras alfabetizadoras dos municípios em questão, cujo foco foram os desafios e as possibilidades do planejamento da alfabetização em tempos pandêmicos. Assim sendo, tendo em vista o formato da ação extensionista, não foram mapeadas as aprendizagens dos alunos.
} 


\section{Elementos teóricos acerca do planejamento de práticas alfabetizadoras}

Tomando como premissa o objetivo de compreender os desafios e as possibilidades das alfabetizadoras ao elaborarem suas práticas pedagógicas em tempos da Covid-19, entende-se como fundamental evidenciar alguns conceitos que subsidiaram a categorização e a análise dos dados por ora apresentados, a saber, alfabetização, letramento e planejamento.

No que diz respeito à alfabetização, Galvão (2010) ressalta que antes mesmo de frequentarem a Educação Infantil, as crianças interagem com a cultura escrita buscando compreender elementos que a constitui, seus usos e suas funções. Na esteira desse entendimento, Soares (2004) afirma ser importante nomear de forma distinta a aquisição do código alfabético e as práticas envolvendo o uso desse código. Nesse sentido, a autora ressalta que a alfabetização está vinculada à primeira, sendo, portanto, referente ao aprendizado da técnica e do domínio do código convencional da leitura e da escrita. O letramento, por sua vez, trata das práticas que envolvem os usos sociais da leitura e da escrita. Tais definições têm importantes implicações no que tange ao ensino remoto em tempos pandêmicos, atentando para as especificidades implicadas em seus processos e suas articulações com os espaços, tempos e dinâmicas das casas das crianças e de suas famílias.

Perceber a alfabetização por esse viés é considerar uma perspectiva de aquisição e também de expressão e compreensão, ou seja, é conceber que a criança precisa identificar, por exemplo, as diferenças no formato das letras e dos sons que elas representam e entender as possíveis combinações entre elas; as quais se deram por meio de outros modos de intenção e de intervenção pedagógica, a partir do ensino remoto. Importante destacar, que o momento de aquisição não se dá isolado das práticas sociais que envolvem a língua escrita, ao contrário, a alfabetização como aprendizagem da técnica ocorre no contexto do letramento, o qual foi totalmente reorganizado em tempos de pandemia.

Ao distinguir e nomear de forma diferente a aquisição e o uso da língua escrita, Soares (2004, p. 11) adverte que "[...] defender a especificidade do processo de alfabetização não significa dissociá-lo do processo de letramento"; longe disso, o processo de "[...] entrada no mundo da escrita" ocorre "pela aquisição do sistema convencional de escrita" juntamente ao "[...] uso desse sistema em atividades de leitura e escrita, nas práticas sociais que envolvem a língua escrita" (SOARES, 2004, p. 25). Assim, para a autora, é necessário que as práticas pedagógicas contemplem de forma integrada a alfabetização e o letramento, sem perder de vista, todavia, a singularidade de cada um desses processos. O que repercutiu fortemente nas práticas pedagógicas alfabetizadoras 
de professores e professoras de todo o país porque outras/novas práticas sociais, entrecruzadas pela cultura letrada das casas, deram o tom nas dinâmicas escolares.

Há de se considerar, nessa perspectiva, que, por meio de diferentes interações, as crianças criam estratégias e hipóteses sobre a escrita, demonstrando interesse pelo seu funcionamento e seus usos; brincam com ela; reconhecem diferenças de gêneros orais e textuais, evidenciando assim, envolverem-se em uma cultura letrada. E, ainda, que mostram, por meio dessas interações estabelecidas entre si e/ou com adultos, seu protagonismo no processo de construção da língua escrita (FERREIRO e TEBEROSKY, 1985; SOARES, 2004; BAPTISTA, 2011). Desse modo, é fundamental que a proposta pedagógica para a alfabetização tenha esses entendimentos como ponto de partida, privilegiando os usos e as funções da língua escrita e não somente a aquisição do código alfabético (GOULART, 2007; GALVÃO, 2010, BAPTISTA, 2011).

Essa discussão, que vem sendo realizada de forma intensa nas últimas décadas no campo da alfabetização e da formação de professores, evidencia que a aprendizagem da escrita não é um processo natural, uma vez que “[...] A escrita, é uma invenção cultural, a construção de uma visualização dos sons da fala, não um instinto" e, por isso, “[...] precisa ser ensinada por meio de métodos que orientem o processo do ler e do escrever" (SOARES, 2016, p. 45). Processo esse que exige a expertise pedagógica para identificar as hipóteses e os níveis das crianças e criar recursos, estratégias e situações que lhes permitam avançar em seus processos de aprendizagens. Para tanto, cabe às professoras e aos professores a mediação e o acompanhamento constantes; a organização da sala de aula enquanto um espaço alfabetizador; incentivar os usos sociais da escrita e da leitura; entre outros elementos que denotam a

[...] importância do trabalho docente presencial, à potência das interações professorcriança e das crianças entre si, às redes de relações e aprendizagens que se processam na sala de aula e que foram obstruídas pelo distanciamento social imposto pela pandemia (RELATÓRIO EM REDE, 2020, p. 193).

Partindo desse entendimento, planejar práticas pedagógicas que possibilitassem a alfabetização de forma associada ao letramento em tempos de pandemia, implicou práticas engendradas nos espaços e nos tempos das residências. Nesse sentido, considerar as especificidades do ensino remoto, não foi uma tarefa fácil para as professoras e professores de todo o Brasil.

Sobre a organização do planejamento, Libâneo (2013, p. 245) salienta que planejar "é uma tarefa docente que inclui tanto a previsão das atividades didáticas em termos da sua organização e coordenação em face dos objetivos propostos, quanto a sua revisão e adequação" no decorrer do próprio processo de ensino. Dizendo de outro modo, o ato de planejar-a organização e a coordenação das práticas pedagógicas incluem a previsão, a revisão e a adequação do ensino, em 
função das formas e dos modos como ele ocorre. Aspectos estes completamente modificados em função do coronavírus.

Refletindo acerca do planejamento em tempos pandêmicos, Ferreira e Barbosa (2020, p. 23) assinalam que,

O fechamento temporário dos prédios escolares e a decisão repentina de interrupcão das aulas presenciais impossibilitou qualquer preparacão, planejamento ou organizacão para que fossem oferecidas alternativas de extensão da rotina escolar no ambiente doméstico, seja em relacão ao planejamento adequado de sequencias didáticas coerentes com tal realidade, no que diz respeito à instrumentalizacão e à formacão docente para o uso de outras ferramentas ou, ainda, em relacão ao oferecimento de suporte técnico, de equipamentos e de infraestrutura operacional aos alunos e aos seus familiares.

Desse modo, o processo de planejar, em tempos tão díspares, se mostrou mais articulado às problemáticas do contexto social e emergiu das necessidades diárias de (re)organização, (re)configuração e (re)invenção do planejamento para a alfabetização no ensino remoto. Teve que considerar, assim, a ausência de interações e intervenções síncronas das professoras no desenvolvimento dos processos cognitivos das crianças no que tange à aquisição da leitura e da escrita.

Diante do exposto, passa-se a tratar na seção seguinte acerca da coleta e da produção dos dados da pesquisa.

\section{Percurso metodológico}

Trata-se de uma pesquisa de cunho qualitativo que visa compreender, a partir das experiências vividas dos seres humanos, perspectivas e interpretações acerca de um determinado assunto (BOGDAN e BIKLEN, 1994; GIL, 2008), neste artigo, a experiência de professoras alfabetizadoras em tempos de pandemia.

Conforme destacado por André e Gatti (2008, p. 9):

\footnotetext{
O uso dos métodos qualitativos trouxe grande e variada contribuição ao avanço do conhecimento em educação, permitindo melhor compreender processos escolares, de aprendizagem, de relações, processos institucionais e culturais, de socialização e sociabilidade, o cotidiano escolar em suas múltiplas implicações, as formas de mudança e resiliência presentes nas ações educativas.
}

Para o caso deste trabalho, a pesquisa qualitativa permitiu identificar e analisar as inúmeras mudanças e os desafios enfrentados na (re)organização, (re)configuração e (re)invenções dos planejamentos das alfabetizadoras, bem como as possibilidades encontradas por elas para 
desenvolvê-los em tempos pandêmicos. Para tanto, a coleta de dados ocorreu por meio do envio de um questionário on-line a todas as docentes que atuavam, em 2020, no ciclo de alfabetização das duas redes de ensino pesquisadas, situadas no Rio Grande do Sul, as quais são identificadas no decorrer do texto como Rede de Ensino 1 (RE 1) e Rede de Ensino 2 (RE 2). Segundo dados do IBGE (2020), a primeira cidade possuía população de 43.171 habitantes e contava com 4.772 matrículas, distribuídas em 16 instituições municipais de Ensino Fundamental. Já o segundo município totalizava a população de 8.350 habitantes e 7 escolas de Ensino Fundamental, as quais atendiam 824 matrículas.

Sobre o instrumento de investigação, cabe salientar que o mesmo foi enviado no mês de março de 2020, isto é, logo no início da pandemia, e era composto de 19 questões, as quais foram distribuídas em três categorias, a saber: Formação; Planejamento; Formação Continuada. Tratavase de questões abertas e fechadas, sendo que as questões abertas permitiram às participantes "responder livremente, usando linguagem própria, e emitir opiniões" (MARCONI e LAKATOS, 2003, p. 204). Já as questões fechadas, possibilitaram sistematizar dados referentes à formação acadêmica das professoras participantes da pesquisa; aos recursos e às estratégias didáticas pensadas, planejadas, produzidas e engendradas para o ensino remoto. Para o caso deste artigo, foram analisadas especificamente as questões abertas e fechadas relativas à categoria do planejamento. Assim, buscou-se mapear as compreensões, os desafios, as produções e as demandas das docentes nos primeiros meses de pandemia no que se referia ao planejamento em tempos pandêmicos, tomando por base a análise de conteúdo de Bardin (2011)

Ao todo, as Redes de Ensino 1 e 2 contavam com 68 professoras atuando no ciclo de alfabetização no ano de 2020. Destas, 28 docentes participaram da pesquisa, as quais correspondem a $41 \%$ das profissionais que atendiam a este segmento. No que se refere à formação acadêmica, todas possuíam Nível Superior, sendo 25 com graduação em Pedagogia e 3 com licenciaturas em Letras, Geografia e Educação no Campo, respectivamente. Dentre elas, 27 alfabetizadoras também contavam com pós-graduação.

Quanto ao tempo de docência, 75\% das participantes atuavam há mais de cinco anos em classes de alfabetização. Contudo, este período variava entre 5 e 23 anos. Quando perguntado, especificamente, sobre o tempo de docência no ciclo de alfabetização, este dado mudou consideravelmente, isso porque, com exceção de 5 docentes, todas as demais trabalhavam há menos de 6 anos junto às turmas deste ciclo. Tais dados evidenciam um grupo formado por professoras com uma trajetória profissional, em certa medida, consolidada, tendo em vista os mais de 5 anos de atuação em sala de aula. Contudo, reverbera que, em tempos de pandemia, mesmo 
profissionais experientes foram desafiadas quanto à organização do planejamento; tendência observada também nas respostas de professores e professoras à pesquisa Alfabetização em Rede (2020) e que será discutida na seção seguinte.

\section{O planejamento de práticas alfabetizadoras: análise dos resultados}

Compreendendo as implicações conceituais que envolvem os processos de alfabetização e de letramento e sua emergência em tempos pandêmicos, apresenta-se nesta seção os desafios e as possibilidades encontradas pelas professoras participantes da pesquisa no que tange ao planejamento.

De início, destaca-se que os dados da pesquisa evidenciaram, de forma recorrente, os sentimentos de ausência, de "distanciamento", de "não estar presente", de "não estar perto", de "não poder sentir a turma", de "não poder falar com a criança", asseverando o entendimento acerca da importância da presencialidade. Conforme as narrativas, a distância existente entre as professoras e os alunos foi demarcada inicialmente como um dos principais desafios enfrentados no momento do planejamento, pois havia o reconhecimento, por parte das docentes, de que os elementos e/ou as habilidades do processo de alfabetização devem ser sempre permeados pela presença, pela intervenção intencional e pela mediação pedagógica do professor - semelhante aos dados apresentados no Relatório Parcial da pesquisa Alfabetização em Rede (2020).

São elucidativas, a esse respeito, as palavras da Professora $22^{3}$, vinculada à RE 2 , ao ressaltar que "a alfabetização é baseada no diálogo. Imagina enviar atividades para fazer em casa sem você poder falar com a criança, explicar que o som da letra é de tal forma. É muito complicado. Me sinto inútil.”. Na esteira desse entendimento, a Professora 4, da RE 1, destaca que:

\footnotetext{
[...] não estávamos habituados a dar aulas à distância, principalmente na alfabetização, estou fazendo meu papel como professora, pesquisando, proporcionando uma aprendizagem variada e ao mesmo tempo comprometida com os objetivos do primeiro trimestre. No entanto, não posso garantir que tudo está saindo como eu gostaria porque não estou perto suficiente para observar os avanços e as dificuldades de cada um. [...] Ensinar a ler a distância tem sido um desafio diário, é angustiante para mim.
}

Nesse sentido, destaca-se a relevância da presencialidade na alfabetização, a qual permite acompanhar e intervir pedagogicamente no processo de aprendizagem das crianças. $\mathrm{O}$ fato de o ensino ter continuidade de maneira remota não possibilita essa interação. Por mais que tenham sido utilizadas ferramentas e aplicativos tecnológicos, como será mencionado a seguir, as práticas

\footnotetext{
${ }^{3}$ Para preservar a identidade das professoras participantes do estudo, elas serão identificadas pela ordem de envio de suas respostas ao questionário.
} 
desenvolvidas nas escolas têm especificidades que não podem ser deslocadas para outros espaços e tempos (DIAS e SMOLKA, 2021).

Para dar conta de tais desafios, e tendo que enfrentar a ausência de interações e intervenções no processo de aprendizagem da leitura e da escrita, muitas docentes afirmaram utilizar-se de diferentes recursos e ferramentas tecnológicas para tentar uma aproximação com suas turmas, buscando manter o vínculo com as crianças e/ou promover ações sistemáticas que objetivavam a alfabetização. Nesse sentido, observou-se de forma geral, que os primeiros contatos com as crianças e os primeiros planejamentos organizados pelas alfabetizadoras tiveram um caráter mais afetivo, de manutenção de vínculos e de "revisão" dos conteúdos até então trabalhos, do que efetivamente o desenvolvimento de um trabalho pedagógico que intencionava dar continuidade à alfabetização. O que se viu, portanto, foi o ensino remoto, inicialmente, cumprindo uma função socializadora (ARAÚJO, 2020).

Assim como evidenciaram outros estudos, as crianças e as professoras, foram, aos poucos, (re)construindo o vínculo sem a necessária presença física (AMORIM e AMARAL, 2020). Nessa direção, destacam-se as aulas síncronas, desenvolvidas por meio do uso de plataformas digitais, assim como os áudios e as videochamadas produzidas pelas professoras, pelos familiares e pelas próprias crianças, os quais, em muitos casos, elucidaram outras maneiras viáveis de estabelecer vínculos e de tornar o ensino e a aprendizagem, neste momento emergencial, factível.

O uso de diferentes estratégias para uma aproximação entre professoras e crianças exigiu, também, o conhecimento das condições de acesso à internet e da disponibilidade das famílias em participar desses momentos, haja vista que se tratava de crianças que, nem sempre, sabiam manusear os suportes tecnológicos (computadores, tablets ou celulares) e/ou as plataformas digitais de comunicação. Assim sendo, para desenvolver essas ações, foi necessário o exercício de escuta, de alteridade, de construção coletiva (professoras e famílias), de efetivação de um planejamento participativo, uma vez que planejar é um ato participativo e comunitário, e que deve surgir das necessidades próprias de um grupo (MENEGOLLA e SANT’ANNA, 2014).

Todavia, essa realidade tecnológica e de encaminhamento das atividades não foi igual para todas as professoras. Em linhas gerais, pode-se dizer que a análise dos dados aponta para um distanciamento entre as duas redes municipais investigadas no que se refere ao uso das tecnologias, ao modo como as atividades foram encaminhadas e à frequência e à periodicidade da organização dos planejamentos.

Quanto a este último elemento, evidenciou-se que na RE 2 os planejamentos foram, majoritariamente, produzidos quinzenalmente (87,5\%), ao passo que na RE $145 \%$ das 
alfabetizadoras afirmaram o planejar diariamente. Em geral, o tempo planejado pelas professoras para a execução das atividades pelos alunos mostrou-se bastante diverso. Enquanto algumas indicaram programar atividades para um período aproximado de duas horas, outras afirmaram planejar seguindo aquele que seria o turno e o tempo da escola. Entretanto, é necessário salientar que os tempos e os espaços escolares, bem como, suas rotinas e os atores sociais que o integram, se distinguem, e muito, das dinâmicas, sujeitos e rotinas das residências das crianças. A esse respeito, Inês Dussel (2020) chama a atenção para a forma como a sala de aula se constitui em um entorno sociotécnico particular que habilita formas de trabalhar os saberes, ao mesmo tempo em que organiza os corpos e os tempos em atividades que propõem desafios intelectuais. Ademais, assinala que o deslocamento do espaço escolar para o espaço doméstico, além de instituir a "domicilização" da escola, com a inserção de todos os seus cômodos, artefatos e partícipes, asseverou as desigualdades pré-existentes e inseriu, de forma mais intensa, os familiares na mediação do ensino e da aprendizagem.

Em consonância a essa assertiva, foi frisado pela Professora 6 da RE 2, a necessidade, na elaboração do planejamento, de um equilíbrio, pois além de os familiares estarem trabalhando e terem dificuldade em executar a atividade como planejada, haja visto que não são professores e muitos, ainda, "não conseguem auxiliar os filhos nem em tarefas simples".

$\mathrm{Na}$ esteira desse entendimento, várias participantes mencionaram propor atividades que as crianças pudessem desenvolver de forma autônoma, sem necessitar da mediação, intervenção e/ou interação dos pais e/ou responsáveis. Tal preocupação se deu em função da família, possivelmente, não saber conduzir a atividade com a intencionalidade pedagógica planejada, visto que os responsáveis poderiam não ser professores, não possuir conhecimentos teóricos e didático-pedagógicos voltados ao processo de alfabetização e, em alguns casos, não ser alfabetizados.

As pesquisas de Melo e França-Carvalho (2020) e de Sobrinho (2020) vão ao encontro destes dados. Segundo os autores, várias docentes têm procurado elaborar atividades de fácil orientação, com linguagem acessível aos pais e, de forma recorrente, produzido vídeos explicativos para direcionar e orientar as atividades. Tal preocupação emerge da compreensão de que as famílias não são responsáveis, mas co-partícipes dos processos de ensino e de aprendizagem das crianças. E, por isso, as professoras precisaram planejar não só as atividades a serem desenvolvidas, mas também a maneira como apresentar a orientação da tarefa, assim como o recurso mais adequado para este fim, reafirmando, desse modo, a concepção do planejamento como um roteiro de uso diário, como um guia do trabalho a ser desenvolvido, "um roteiro que direciona uma linha de pensamento e ação" (MENEGOLLA e SANT’ANNA, 2014, p. 44). 
Além do desafio da distância existente entre professoras e alunos e da preocupação com a realidade das famílias, há de se ponderar, segundo as respostas dos questionários, o tempo que cada criança levaria para realizar a atividade nos espaços e tempos da casa, assim como a disponibilidade dos pais e/ou responsáveis para mediar os processos de ensino e de aprendizagem, já que muitos permaneceram trabalhando diariamente; para acompanhar as atividades dos filhos no tempo programado; e dar um retorno imediato às professoras. Segundo Dias e Smolka (2021, p. 239), essas dificuldades podem ser "impeditivas de uma maior participação nas atividades remotas, e até mesmo, da aprendizagem do aluno no período". Como mencionado nos questionários pelas professoras participantes da pesquisa, a possibilidade ou não de os pais e/ou responsáveis auxiliarem as crianças resultam em situações concretas de aprendizagens completamente díspares, uma vez que é possível observar, por meio das devolutivas e/ou dos primeiros encontros síncronos, que aquelas que estavam tendo o acompanhamento de um adulto e/ou responsável estavam apresentando avanços mais significativos em relação à aquisição da leitura e da escrita do que aquelas crianças que não dispunham deste auxílio.

$\mathrm{Na}$ esteira da (re)organização e da (re)configuração da aula em tempos de pandemia, se enquadrou o desafio de articular o planejamento do tempo de sala de aula ao tempo de execução das atividades pelas crianças em casa, à disponibilidade e ao retorno das famílias. Bem como, dos entendimentos e das compreensões dos pais sobre os tempos implicados no processo de alfabetização. Como afirmou a Professora 3, da RE 1, "O tempo para execução é organizado pelos pais, alguns enviam na mesma tarde da atividade, outros à noite, outros após concluírem duas ou três atividades".

Em relação a esse aspecto, é significativo o registro de outras duas professoras. A Professora 9 (RE 2), que informou planejar as atividades diariamente, mas solicitar o retorno dos pais até o final de semana, tendo em vista que eles trabalhavam e precisavam de mais tempo para se organizarem. E a Professora 16 (RE 1) que indicou levar em consideração que os alunos nem sempre dispunham de computador para realizar suas atividades, sendo a maior parte delas realizada por meio do celular dos pais, os quais, muitas vezes, trabalhavam com o dispositivo no horário das aulas. Observa-se que o ato de planejar, como frisou Menegolla e Sant'Anna (2014), demanda um olhar atento à realidade dos sujeitos envolvidos no processo, assim como à disponibilidade material e humana dos recursos necessários para o processo de alfabetizar de maneira remota, no caso desta pesquisa.

No cenário de (re)organização e (re)configuração do planejamento da alfabetização por meio do ensino remoto, constatou-se que foram (re)inventados o uso de recursos, de estratégias de ensino 
e do acompanhamento do processo de aprendizagem das crianças, além dos saberes docentes. Os resultados apontaram que os principais recursos utilizados nos planejamentos das alfabetizadoras para o ensino remoto, no ano de 2020, foram: i) Grupo I - folhas impressas, folhas fotocopiadas e livros didáticos - semelhantes aos recursos utilizados em tempos considerados "normais"; ii) Grupo II recursos digitais - tais como Whatsapp, links literários, plataforma Google Classroom, vídeos explicativos produzidos pelas professoras e/ou disponíveis na internet e aplicativos on-line; e, iii) Grupo III - jogos, alfabetos móveis (confeccionados pelas crianças), kits de atividades, material dourado e de contagem, objetos da casa - auxiliares nas explicações dos vídeos e fotos. Essa diversidade de recursos anunciada pelas professoras evidencia que os objetivos a serem alcançados e as possibilidades humanas e materiais determinam não só os procedimentos a serem adotados, mas também os recursos contemplados nos planejamentos (MEGEGOLLA e SANT'ANNA, 2014).

Algumas ressalvas são importantes sobre essa questão. A primeira delas é que as duas redes de ensino investigadas atendem a um número significativo de estudantes residentes no meio rural, o que trouxe implicações para as escolhas quanto ao envio do material impresso e ao uso de recursos digitais. É elucidativo o fato de um dos municípios, o qual integra a RE 2, ter iniciado o encaminhamento das atividades de forma on-line, via Whatsapp e Facebook, e, posteriormente a uma avaliação do ínfimo número de retornos e dos acessos das famílias à internet, optar por disponibilizar na escola as atividades de maneira impressa, no formato de apostilas com periodicidade mensal, para que os pais e/ou responsáveis buscassem e se comprometessem a devolver as mesmas. Outro movimento relatado pelas professoras de ambas as redes de ensino, devido a essa dificuldade de acesso à internet e à falta de retorno das atividades por parte das famílias, foi o deslocamento de algumas profissionais até pontos próximos às residências das crianças para entregar e/ou buscar as atividades.

A esse respeito, dados do IBGE (2018) apontam que, em âmbito nacional, na área rural apenas $49,2 \%$ da população utiliza internet em seus domicílios. De forma semelhante, ao serem questionados sobre qual foi o maior desafio para a realização de ações durante a execução de um projeto de conectividade, que envolvia escolas e famílias durante a pandemia, 65\% dos professores envolvidos assinalaram ser a falta de acesso à tecnologia de parte dos alunos, a qual impossibilitava o contato e a mediação necessários à aprendizagem (MELO e FRANÇA-CARVALHO, 2020).

O que se evidencia, a partir dos resultados apresentados e da pesquisa referida, é que, apesar dos inúmeros esforços, da construção, em muitos casos, de um planejamento voltado para as condições das famílias e das crianças, o ensino remoto não abarcou a realidade de todos os 
estudantes da Educação Básica brasileira. "O que se promove ainda é distante de uma experiência educativa que traz consigo o caráter formador, que assegura a dialogicidade e reflete sobre o contexto de vida de cada aluno" (SOUZA e MAGNONI JÚNIOR, 2020, p. 18). Realidade essa apontada pelas integrantes da pesquisa, haja vista mencionarem nos questionários a impressão de, muitas vezes, apesar de todos os esforços empreendidos, não darem conta do processo de alfabetização e/ou de atingir a todos os estudantes.

É válido ressaltar que todos os recursos mencionados pelas docentes (folhas impressas, folhas fotocopiadas e livros didáticos, uso do Whatsapp, links literários, plataforma classroom, vídeos e aplicativos on-line, jogos, alfabetos móveis, kits de atividades, material dourado, material de contagem e objetos da casa) foram utilizados de forma concomitante, considerando a realidade de cada rede de ensino e as especificidades de cada turma, na medida em que as alfabetizadoras percebiam o ensino e a aprendizagem como elementos de "dependência" e buscavam compreender como as crianças estavam ou não dando conta das atividades propostas. Também se identificou que o mesmo recurso era utilizado com finalidades distintas. Bons exemplos são os áudios de Whatsapp, que ora eram produzidos pelas professoras com a intencionalidade de orientar o desenvolvimento das atividades, de explicar algum conteúdo e de se comunicar com as famílias, ora eram utilizados pelas próprias crianças para dar o retorno das atividades (realizar a leitura de uma palavra, de uma frase, de textos; para expressar suas dificuldades, entre outros).

Da mesma maneira, observou-se certa preocupação por parte das professoras em articular os elementos especificos do processo de alfabetização com as realidades que estavam sendo vivenciadas pelas crianças, a fim de ressignificar o contato com outras ações e práticas de leitura e de escrita cotidianas, asseverando uma perspectiva voltada para o letramento. As palavras de Soares (2016, p. 346) relembram, nessa perspectiva, que uma criança considerada alfabetizada e letrada é “[...] aquela que não só sabe ler e escrever, mas também domina habilidades básicas de leitura e escrita necessárias para a participação em eventos de letramento tão frequentes nas sociedades contemporâneas".

O relato da Professora 12, vinculada à RE 1, demonstra esse cuidado, tendo em vista afirmar que ao planejar: "Busco histórias que trabalhem a casa (família), depois organizo com poema, com construção de brinquedos de sucatas, com a construção da casa engraçada a partir da poesia, do caminho da casa até a escola [...]”. Nessa direção, outras professoras relataram propor desafios para as famílias que envolvessem a escrita, sugerir atividades e brincadeiras para a família realizar coletivamente, incentivar a identificação do uso da escrita em situações cotidianas como a construção da lista de compras do supermercado, entre outras. Como se observa, as propostas das 
alfabetizadoras buscaram promover, mesmo em meio à pandemia, "a participação das crianças em práticas autênticas de leitura e de escrita", nas quais elas puderam interagir com este objeto do conhecimento (MONTEIRO e BAPTISTA, 2009. p. 40).

Oportuno destacar, desse modo, que:

\begin{abstract}
Ser professor em época de pandemia é bem mais complexo ainda. Embora se possa contar com um número de professores experientes no uso de tecnologias, nem todos estão familiarizados com elas. Assim, muitos docentes tiveram de começar, de forma muito apressada, a adquirir um nível mínimo de competências para lidar com os recursos tecnológicos. Ou seja, houve um esforço titânico dos professores para aprender rapidamente sobre esses aparatos tecnológicos e aplicá-los com finalidades educacionais. (AMORIM e AMARAL, 2020, p. 82).
\end{abstract}

Nesse sentido, semelhante à experiência mencionada no excerto, as docentes investigadas não haviam tido experiência com o ensino remoto, tão pouco com o ato de planejar práticas pedagógicas para serem desenvolvidas por meio desta modalidade. Isso posto, o que se percebeu nesta pesquisa foram intensas (re)organizações, (re)configurações e (re)invenções do planejamento das práticas pedagógicas alfabetizadoras na tentativa de contribuir com os processos de aprendizagem da leitura e da escrita de seus alunos em tempos pandêmicos. E, que, mesmo estas práticas sendo realizadas em outros espaços e tempos, como as residências das crianças, elas foram engendradas de modo que despertassem o interesse, e que fossem, sobretudo, apropriadas como forma de inclusão social (BAPTISTA, 2009).

\title{
5 Considerações Finais
}

Teve-se como objetivo, neste artigo, compreender os desafios e as possibilidades encontradas por alfabetizadoras, de dois municípios do Rio Grande do Sul, no planejamento de suas práticas pedagógicas em tempos da Covid-19.

As análises foram realizadas a partir do retorno a um questionário on-line de 28 professoras enviado logo nos primeiros meses do isolamento social; período este em que o ensino remoto estava sendo implementado. Os dados possibilitaram observar que, semelhante ao que ocorreu em diferentes partes do Brasil e do mundo, as participantes da pesquisa estavam constantemente avaliando e (re)organizando o seu planejamento a fim de dar seguimento ao processo de alfabetização, bem como atingir o maior número possível de crianças.

Em meio a essas (re)invenções, identificou-se que as possibilidades encontradas pelas professoras configuram-se como um conjunto de estratégias que emergiram a partir das demandas desse momento e do distanciamento físico existente entre docentes e alunos. Assim, áudios, vídeos, 
atividades escritas - produzidos, indicados e forjados na interlocução com os objetivos do planejamento - passaram a ser enviados via Whatsapp e Facebook ou retirados na escola. Para explicar o conteúdo e manter o vínculo com as crianças, as docentes se propuseram a produzir vídeos, realizar chamadas síncronas; se colocaram à disposição quase que de forma integral; e, por vezes, se deslocaram para levar as atividades ao alcance das crianças que não tinham acesso à internet. Ademais, (re)organizaram não só o formato do planejamento, mas também a periodicidade do mesmo, sendo a partir de então estruturados diária ou quinzenalmente. Frequência esta, provavelmente, distinta da realizada anteriormente à suspensão das aulas presenciais.

Tais ações evidenciaram que, além de (re)configurar e (re)organizar seus planejamentos, de usar inúmeros e diversos recursos e estratégias possíveis e disponíveis, as professoras também tiveram de (re)configurar e (re)inventar seus fazeres e saberes docentes, em função das limitações enfrentadas pela ausência das aulas presenciais. Para além, as narrativas dessas profissionais revelaram que esse processo foi árduo e permeado por desafios diários, haja vista que, muitas delas, não tinham formação para trabalhar com a tecnologia, a qual se pautou, nesse momento de ensino remoto, como umas das ferramentas basilares do processo de ensino.

Conforme destacado no decorrer do artigo, nos primeiros meses de ensino remoto, os desafios no ato de planejar em tempos de pandemia, para o grupo de participantes desta pesquisa, esteve para além do elaborar propostas pedagógicas alfabetizadoras que se diferenciassem daquelas ministradas nos espaços e tempos das salas de aulas. Ele envolveu também, e senão principalmente, considerar: i) a disponibilidade de cada família para acompanhar e executar as atividades propostas; ii) a busca pela manutenção do vínculo; iii) a observância das condições de acesso à internet e de uso das ferramentas digitais pelas mesmas; e iv) a tentativa de articular, ao seu planejamento, práticas de alfabetização engendradas às culturas letradas vivenciadas nos espaços e nos tempos das casas.

Os resultados também mostram que, em um primeiro momento, as professoras identificaram que as crianças que possuíam acesso à internet, bem como um acompanhamento de um responsável para o desenvolvimento das atividades propostas vinham avançando em seu processo de alfabetização, enquanto que àquelas que não dispunham destes estavam sendo prejudicados no que tange à aprendizagem da leitura e da escrita.

Oportuno destacar que os resultados desta pesquisa apontam dados iniciais advindos das primeiras práticas alfabetizadoras remotas das professoras participantes do estudo. Assim sendo, o que se coloca é a necessidade de continuidade desse acompanhamento de modo à melhor mapear 
não somente os processos de ensino, mas também as aprendizagens produzidas em e meio a estes novos/outros/díspares processos educativos.

\section{Referências}

AMORIM, Rejane M.; AMARAL, Arlene de P. Alfabetização por meio virtual: Alice no mundo da pandemia. Revista Aproximaşão. vol. 02. núm. 05. out/nov/dez, 2020. p.7-19. Disponível em: https://revistas.unicentro.br/index.php/aproximacao/article/view/6703/4631 . Acesso em: 27 fev. 2021.

ANDRÉ, Marli e GATTI, Bernadete. Métodos Qualitativos de Pesquisa em Educação no Brasil: origens e evolução. 2008. Disponível em: https://www.uffs.edu.br. Acesso em: 15 Jun. 2020.

BARDIN, Laurence. Análise de conteúdo. 13. ed. São Paulo: Edições 70, 2011.

BAPTISTA, Mônica C. Alfabetização e letramento em classes de crianças menores de sete anos: direito da criança ou desrespeito à infância? In: GONÇALVES, Adair Vieira; PINHEIRO, Alexandre dos Santos (Orgs.). Nas trilhas do letramento: entre teoria, prática e formação docente. Campinas: Mercado de Letras; Dourados: Editora da Universidade Federal de Dourados, 2011. p. 227-257.

BAPTISTA, Mônica C. Crianças menores de sete anos, aprendizagem da língua escrita e o ensino fundamental de nove anos. In: BRASIL. Ministério da Educação. Secretaria de Educação Básica. A criança de 6 anos, a linguagem escrita e o ensino fundamental de nove anos: escrita em turmas de crianças de seis anos de idade. Belo Horizonte: UFMG, FaE, CEALE, 2009, p. 13-25.

BOGDAN, Roberto C.; BIKLEN, Sari Knopp. Investigação qualitativa em educação. Tradução Maria João Alvarez, Sara Bahia dos Santos e Telmo Mourinho Baptista. Porto: Porto Editora, 1994.

DIAS, D. P.; SMOLKA, A. L. B. Das (im)possibilidades de se alfabetizar e investigar em condições de isolamento social. Revista Brasileira de Alfabetizaação. no 14. p. 228-244. 2021. Disponível em: https://revistaabalf.com.br/index.html/index.php/rabalf. Acesso em: 21 out. 2021. DOI: https://doi.org/10.47249/rba.vi14

DUSSEL, Ines. La escuela en la pandemia. Reflexiones sobre lo escolar en tiempos dislocados. Práxis Educativa, Ponta Grossa, v. 15, 2016482, p. 1-16, 2020. Disponível em:

https://revistas2.uepg.br/index.php/praxiseducativa/article/view/16482. Acesso em: 31 maio 2020. DOI: https://doi.org/10.5212/PraxEduc.v.15.16482.090.

FERREIRA, Luciana Haddad; BARBOSA, Andreza. Lições de quarentena: limites e possibilidades da atuação docente em época de isolamento social. Práxis Educativa, Ponta Grossa, v. 15, e2015483, p. 1 - 24, 2020. Disponível em:

https://revistas2.uepg.br/index.php/praxiseducativa/article/view/15483. Acesso em: 31 maio 2020. DOI: https://doi.org/10.5212/PraxEduc.v.15.15483.076.

FERREIRO, Emília e TEBEROSKY, Ana. A psicogênese da lingua escrita. Porto Alegre: Artes Médicas. 1985. 
GALVÃO, Ana Maria de Oliveira. História das culturas do escrito: tendências e possibilidades de pesquisa. In: MARINHO, Marildes e CARVALHO, Gilcinei Teodoro (Orgs.). Cultura escrita e letramento. Belo Horizonte: Editora UFMG, 2010. p. 218-248.

GIL, Antonio Carlos. Como elaborar projetos de pesquisa. 4. ed. São Paulo: Atlas, 2008.

GOULART, Cecília. A organização do trabalho pedagógico: alfabetização e letramento como eixos orientadores In: BEAUNCHAMP, Jeanete; PAGEL, Sandra Denise; NASCIMENTO, Aricélia Ribeiro do. (Orgs.) Ensino fundamental de nove anos: orientações para a inclusão da criança de seis anos de idade Brasil: Ministério da Educação, Secretaria de Educação Básica, 2007. p. 8596.

GUIZZO, Bianca S.; MARCELLO, Fabiana de A.; MULLER, Fernanda. A reinvenção do cotidiano em tempos de pandemia. Educ. Pesqui., São Paulo, v. 46, e238077, p. 1-18, 2020. Disponível em: https://www.scielo.br/j/ep/a/ybM6TZ8MvPmdLN8HzqgFZKS/?lang=pt. Acesso em: 15 Jun. 2020. DOI: https://doi.org/10.1590/S1678-4634202046238077.

IBGE. Instituto Brasileiro de Geografia e Estatística. Censo Brasileiro de 2018 - 2020. Rio de Janeiro: IBGE, 2020.

IBGE. Instituto Brasileiro de Geografia e Estatística. Rio de Janeiro: IBGE, 2018.

LIBÂNEO, José Carlos. Didática. 2 ed. São Paulo: Cortez, 2013.

LUDOVICO, Franciele M.; MOLON, Jaqueline; FRANCO, Sérgio R. K., BARCELLOS, Patrícia da Silva C. COVID-19: desafios dos docentes na linha de frente da educação. Interfaces Científicas, Número Temático - Cenários escolares em tempo de Covid-19 na Pós-Quarentena. Aracaju, v.10, n.1. p. 58 - 74, 2020. Disponível em:

https://periodicos.set.edu.br/educacao/article/view/9166/4129. Acesso em: 10 jan. 2021. DOI: https://doi.org/10.17564/2316-3828.2020v10n1p58-74.

MARCONI, Marina de Andrade; LAKATOS, Eva Maria. Fundamentos da metodologia científica. 5 ed. São Paulo: Atlas, 2003. Disponível em

https://docente.ifrn.edu.br/olivianeta/disciplinas/copy_of_historia-i/historia-ii/china-e-india. Acesso em: 31 maio 2020.

MELO, Raimunda Alves; FRANÇA-CARVALHO, Antonia D. A produção de materiais didáticos para o desenvolvimento de atividades pedagógicas não presenciais durante a pandemia do coronavírus. Revista Epistemologia e Práxis Educativa. Teresina, ano 03, n. 03, v. 03, set./dez. 2020. p. 1-21. Disponível em:

https://revistas.ufpi.br/index.php/epeduc/article/view/12148/7089. Acesso em: 20 fev. 2021. DOI: https:// doi.org/10.26694/epeduc.v3i3.12148.

MENEGOLLA, Maximiliano; SANT'ANNA, Ilza M. Por que Planejar? Como Planejar?: currículo, área, aula. 22 ed. Petrópolis, RJ: Vozes, 2014. 
MONTEIRO, Sara M.; BAPTISTA, Monica. Dimensões da proposta pedagógica para o ensino da Linguagem Escrita em classes de crianças de seis anos. In: BRASIL, Ministério da Educação. Secretaria de Educação Básica. A criança de 6 anos, a linguagem escrita e o ensino fundamental de nove anos: escrita em turmas de crianças de seis anos de idade. Belo Horizonte: UFMG, FaE, CEALE, 2009, p. 29-67.

MOREIRA, Jose A.; SCHLEMER, Eliane. Por um novo conceito e paradigma de educacão digital onlife. Revista UFG, V. 20, (26), 63438, p. 1-35. 2020. Disponível em: https://www.revistas.ufg.br/revistaufg/article/view/63438/36079. Acesso em: 15 Jun. 2020. DOI: https://doi.org/10.5216/revufg.v20.63438.

NÓVOA, Antonio. Conversa com António Nóvoa - A educação em tempos de pandemia. 2020. Disponível em: http://geonauta.com.br/sala-dos-professores/cartografia-digital/lives- sobreeducao-e-ensino-a-distncia/432. Acesso em: 10 jun. 2020.

RELATÓRIO EM REDE, Alfabetização. Alfabetização em Rede: uma investigação sobre o ensino remoto da alfabetização na pandemia Covid-19 - Relatório Técnico (Parcial). Revista Brasileira De Alfabetização, (13), 2020, p. 185-201. Disponível em:

http://revistaabalf.com.br/index.html/index.php/rabalf/article/view/465. Acesso em: 04 jan. 2021. DOI: https://doi.org/10.47249/rba2020465.

RIO GRANDE DO SUL. Decreto Estadual n 55.115, de 12 de março de 2020. Diário Oficial Estadual, Porto Alegre, p. 1-2, 2020. Disponível em:

http://www.al.rs.gov.br/legis/M010/M0100099.ASP?Hid_Tipo=TEXTO\&Hid_TodasNormas $=66156 \& \mathrm{~h}$ Texto $=\&$ Hid_IDNorma $=66156$. Acesso em: 18 jun. 2020.

SOARES, Magda. Alfabetização: a questão dos métodos. São Paulo: Contexto, 2016.

SOARES, Magda. Alfabetização e letramento. São Paulo: Contexto, 2004.

SOBRINHO, Patrícia J. Oportunidades e desafios da educação pública (Ensino Fundamental e Médio) em tempos de pandemia. Revista Aproximação. vol. 02. núm. 05. out/nov/dez, 2020. p. 7785. Disponível em: https://revistas.unicentro.br/index.php/aproximacao/article/view/ 6687. Acesso em: 27 fev. 2021.

SOUZA, Vitor F.; JÚNIOR MAGNONI, Lourenço. O que as estatísticas retratam sobre a educação básica em tempos de covid-19. Revista Epistemologia e Práxis Educativa. Teresina, ano 03, n. 03, v. 03, set./dez. 2020. p. 1-21. Disponível em:

https://revistas.ufpi.br/index.php/epeduc/article/view/11373. Acesso em: 27 fev. 2021. DOI: https://doi.org/10.26694/epeduc.v3i3.11373. 